\title{
A serological comparison of bovine coronavirus strains
}

\author{
A. A. El-Ghorr*, D. R. Snodgrass, F. M. M. Scott, and I. Campbell \\ Moredun Research Institute, Edinburgh, Scotland
}

Accepted November 16, 1988

\begin{abstract}
Summary. Two bovine coronavirus (BCV) strains from diarrheic calf faeces were adapted to grow in HRT 18 cells and compared in immunofluorescence (IF), haemagglutination inhibition (HAI) and neutralisation (NT) tests with three other strains of $\mathrm{BCV}$ and a human coronavirus (HCV) strain obtained from other laboratories. Polyclonal antisera against these 6 viruses were raised in rabbits. No significant differences between viruses were detected by IF. In the HAI test the $\mathrm{HCV}$ strain was distinguishable from the $5 \mathrm{BCV}$ strains and serological variation between the BCV strains was shown. HCV could be distinguished by NT test, but all BCV isolates were similar. Two monoclonal antibodies prepared against one of the BCV strains distinguished $\mathrm{HCV}$ in all three assays, and detected varying relationships between $\mathrm{BCV}$ strains.
\end{abstract}

\section{Introduction}

Members of the Coronaviridae are assigned to a small number of serological groups. Human coronavirus (HCV-OC 43), haemagglutinating encephalomyelitis virus (HEV) and bovine coronavirus (BCV) form one such group [2, 9, 17]. There has been no extensive serological comparison of BCV strains or investigations into the extent of their relationship with other members of this group. BCV strains $\mathrm{M}$ and PQ possessed similar physicochemical and biological properties [3], but differed by counterimmuno-electrophoresis and immunodiffusion [4]. Four British isolates, 1 from the enteric tract and 3 from the respiratory tract, were compared by a neutralisation (NT) test using pig antisera to three of these isolates. There was complete virus neutralisation with homologous sera and significant cross-reactions with heterologous sera [14]. Slight variation in molecular weight of the structural proteins of BCV strains were reported $[5,7,10,12]$.

In this study, a comprehensive serological comparison of $5 \mathrm{BCV}$ strains and a HCV-OC 43 strain was undertaken using polyclonal and monoclonal antibodies in order to investigate possible variation.

* Current address: Institute of Virology, Mansfield Road, Oxford OX1 3SR, U.K. 


\section{Materials and methods}

\section{Viruses}

Three reference BCV strains already adapted to cell culture were obtained from other laboratories. The American M strain of BCV was kindly supplied by Dr. M. S. McNulty, Veterinary Research Laboratory, Belfast [13]; the Canadian PQ strain by Dr. L. A. Babiuk, University of Saskatchewan, Canada [3]; and the British CK strain by Dr. J. C. Bridger at the Institute for Animal Health, Compton [14]. Two Scottish field isolates of BCV (designated $S 1$ and $S 2$ ) were adapted to grow in a human rectal tumour cell line (HRT 18) following initial isolation in bovine fetal tracheal organ culture as described elsewhere [8]. These five BCV strains were biologically cloned by three terminal dilutions and grown in roller cultures in HRT 18 cells [16]. The virus inoculum was pre-treated with $10 \mu \mathrm{g} / \mathrm{ml}$ trypsin for 1 hour at $37^{\circ} \mathrm{C}$ and $1 \mu \mathrm{g} / \mathrm{ml}$ trypsin was incorporated in the maintenance medium.

Human coronavirus OC 43 which had been passaged in newborn mice by intracerebral inoculation was kindly supplied by Mr. G. Winters of the City Hospital, Edinburgh. A 1/ 100 mouse brain homogenate in phosphate buffered saline (PBS) was treated with $10 \mu \mathrm{g} /$ $\mathrm{ml}$ trypsin for 1 hour at $37^{\circ} \mathrm{C}$ and inoculated on to HRT 18 cells. This virus was adapted to this cell line by 5 passages and was detected in cells by immunofluorescence (IF) using ovine anti-BCV/S 1 serum.

\section{Rabbit antisera}

Each of the six virus strains was pelleted by ultracentrifugation [8], and antiserum was raised in a rabbit by intramuscular inoculation of virus pellet emulsified in Freund's complete adjuvant. After 4 weeks, each rabbit received an intramuscular boost of the same virus pellet in Freund's incomplete adjuvant, and was bled out under anaesthesia 2 weeks later.

\section{Monoclonal antibodies}

Mouse monoclonal antibodies to the $\mathrm{BCV} / \mathrm{S} 2$ strain were raised and ascites produced using a standard technique [7]. Hybridoma-containing wells were screened by IF, haemagglutination inhibition (HAI) and NT. Positive hybridomas were cloned by three terminal dilutions. In this study only two monoclonal antibodies were available: MAB/S $2 / 1$ which had the characteristics $\mathrm{IF}^{+}, \mathrm{HAI}^{+}$and $\mathrm{NT}^{+}$, and $\mathrm{MAB} / \mathrm{S} 2 / 2$ which was $\mathrm{IF}^{+}, \mathrm{HAI}^{-}$and $\mathrm{NT}^{+}$. Both were of the $\operatorname{IgG} 2 \mathrm{a}$ isotype, and both reacted with the haemagglutinin protein by Western blotting (data not shown).

\section{Immunofluorescence test}

Confluent monolayers of HRT 18 cells in microtitre plates were inoculated with $10^{3} \mathrm{TCID}_{50}$ of virus, incubated at $37^{\circ} \mathrm{C}$ for 2 days, washed twice with PBS and fixed in acetone. Doubling dilutions of each serum sample were made in PBS and added in duplicate to the fixed cells. After 30 min incubation at $37^{\circ} \mathrm{C}$, the plates were washed twice in PBS and the appropriate FITC conjugate (either goat anti-rabbit or swine anti-mouse; Wellcome) added and incubated at $37^{\circ} \mathrm{C}$ for a further $30 \mathrm{~min}$. The plates were washed twice more in PBS and examined under incident UV light using a Leitz UV microscope. IF titres were recorded as the highest dilutions to provide clear fluorescing cells when compared to uninoculated controls.

\section{Haemagglutination inhibition test}

The HAI test was performed by standard techniques [15]. Each serum sample and monoclonal antibody was extracted with kaolin, treated with rat erythrocytes and heat inactivated. 
Each virus was used at a standard dilution of $8 \mathrm{HA}$ units. Serum samples were double diluted in duplicate and reacted with the virus. The highest titres to completely inhibit the $\mathrm{HA}$ activity of $8 \mathrm{HA}$ units of virus were recorded.

\section{Neutralisation test}

NTs were performed by standard techniques on HRT 18 cell in microplates, using virus at a titre of 20-200 fluorescing cells per microscope field. After incubation at $37^{\circ} \mathrm{C}$ for 2 days, cells were washed, fixed in acetone and the infected cells visualised by IF using a gnotobiotic calf anti-BCV serum and a swine anti-sheep FITC conjugate (equally efficacious with either bovine or ovine immunoglobulins). The recorded titre of serum samples was the highest dilution to cause a $90 \%$ reduction in the number of fluorescing cells compared to the mean of the virus control wells.

\section{Comparison of strains}

The antigenic relationship (R) between the strains was calculated using the formula (1):

$$
\mathrm{R}=100 \sqrt{\mathrm{r} 1 \times \mathrm{r} 2} \%
$$

where $\mathrm{r} 1$ = heterologous titre (strain 2)/ homologous titre (strain 1) and $\mathrm{r} 2=$ heterologous titre (strain 1) / homologous titre (strain 2)

Titres were calculated using the geometric mean of duplicate results. Titres of less than 10 were treated as 5 . A greater than 20 -fold difference in titre in both directions is used as indication of serotype in rotaviruses and picornaviruses [18] and this equates to $\mathrm{R}<5 \%$.

\section{Results}

\section{Virus culture}

During this study no CPE was detected in HRT 18 cells at any stage with any of the strains and the use of trypsin was essential for virus replication. Virus was detected in cell culture by IF and haemagglutination.

\section{Immunofluorescence test}

The $5 \mathrm{BCV}$ strains and the HCV-OC43 strain were not significantly distinct when reacted with polyclonal antisera (Table 1 ) as the lowest calculated $R$ value was $15 \%$ (data not shown).

HCV-OC 43 was clearly distinguished from the bovine strains (Table 1) by the monoclonal antibodies to strain $\mathrm{S} 2$. Both monoclonal antibodies had $\geqslant 32$ fold lower IF titres when tested against the $M$ and $S 1$ strains than against the homologous strain. $\mathrm{MAB} / \mathrm{S} 2 / 2$ in addition had a 32-fold lower IF titre against strain CK.

\section{Haemagglutination inhibition test}

The results of the HAI test are shown in Table 2. HCV-OC 43 was clearly distinguished from the BCV strains by the polyclonal antisera, with $\mathrm{R}=4-9 \%$. Strain BCV/S 1 also showed weaker reactions with the other BCV strains $(\mathrm{R}=5-$ $21 \%$ ). 'One-way' reactions were detected in this test between the CK and $\mathrm{M}$, $\mathrm{CK}$ and $\mathrm{PQ}$, and between the $\mathrm{S} 2$ and $\mathrm{M}$ strains.

$\mathrm{MAB} / \mathrm{S} 2 / 2$ had no HAI activity. MAB/S 2/1 differentiated HCV-OC 43 and also had only a weaker crossreaction with the $\mathrm{BCV} / \mathrm{S} 1$ strain. 
A. A. El-Ghorr et al.

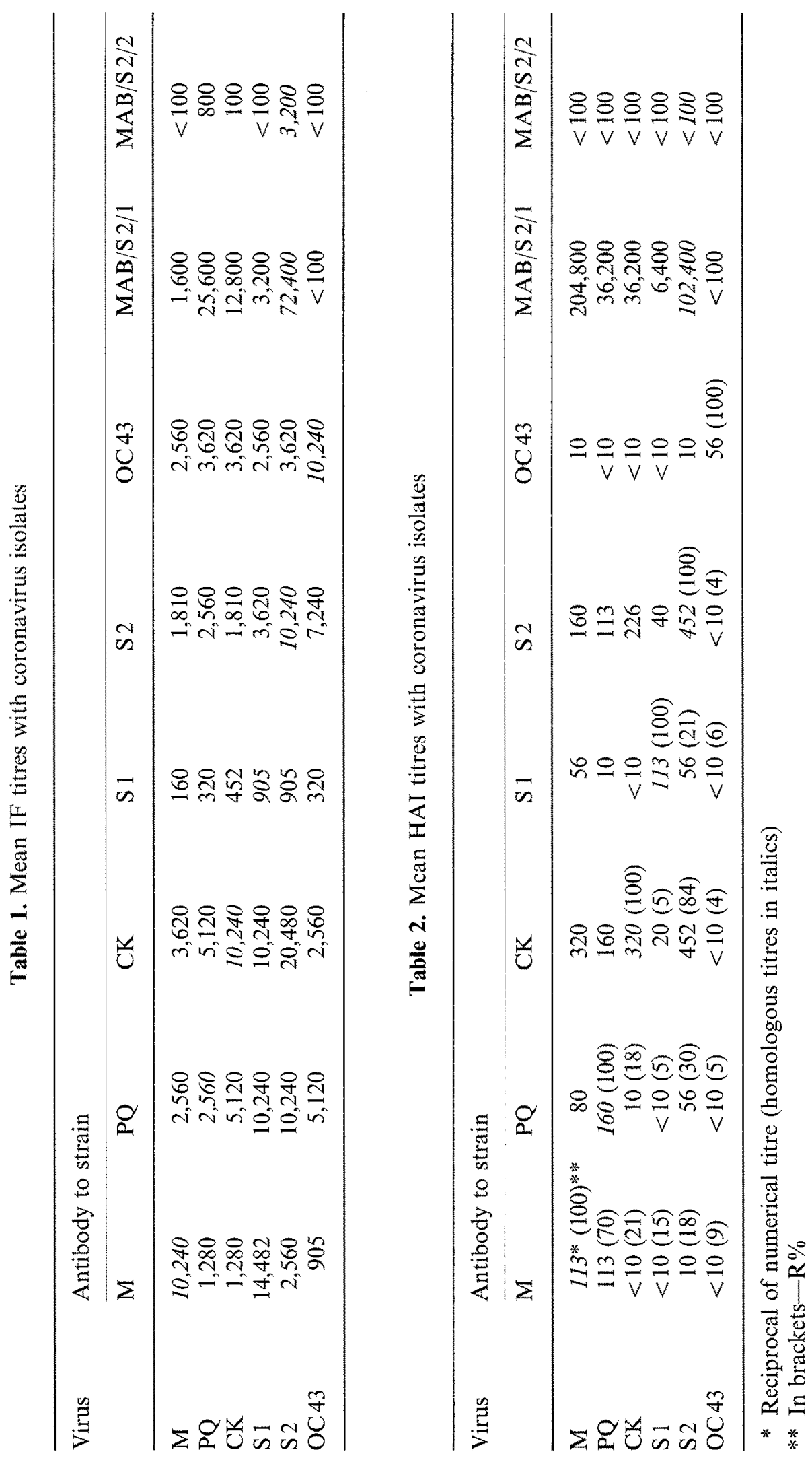




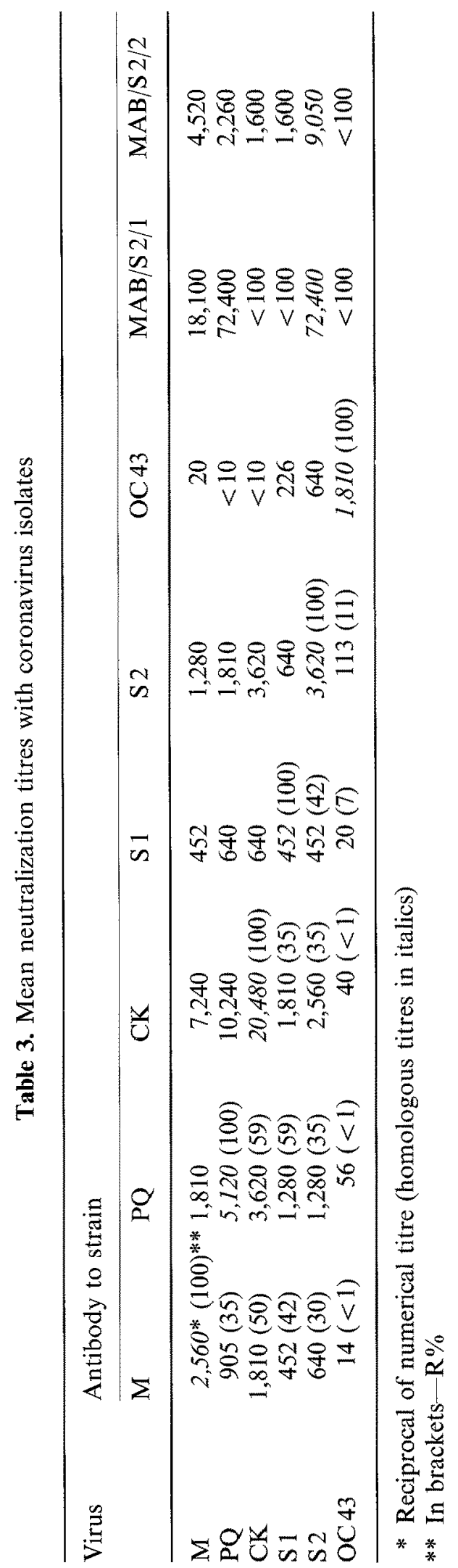




\section{Neutralisation test}

The NT results are shown in Table 3 . HCV-OC 43 was clearly distinct from all the $\mathrm{BCV}$ strains $(\mathrm{R}=1-11 \%)$. A high degree of relatedness was apparent between the BCV strains using polyclonal antisera $(R>30 \%)$.

Both monoclonal antibodies differentiated the HCV-OC 43. MAB/S 2/1 clearly distinguished between $\mathrm{M}, \mathrm{PQ}$, and $\mathrm{S} 2$ on the one hand and $\mathrm{CK}$ and $\mathrm{S} 1$ on the other, while $\mathrm{MAB} / \mathrm{S} 2 / 2$ neutralised all 5 strains of $\mathrm{BCV}$ to a similar extent.

\section{Discussion}

Polyclonal antibodies are directed against many different epitopes on viral proteins and differences may be masked as only a proportion of these epitopes need remain constant for the antiserum to react with the virus. This can be highlighted in the case of BCV by the haemagglutinin and peplomer proteins, both of which elicit neutralising activity [6]. In a neutralisation test, if the peplomer protein remained unchanged, differences in the haemagglutinin protein would not be detected using polyclonal antiserum. This also applied in the case of different epitopes on one protein. On the other hand, monoclonal antibodies may be so specific that minor antigenic differences detected by these antibodies may have no biological significance. Alternatively, monoclonal antibodies may be directed against a common antigen and may not detect important differences between strains. For these reasons both monoclonal and polyclonal antibodies were used in three serological tests to determine the extent of differences between isolates.

Using polyclonal antisera, the relationship of HCV-OC 43 to $\mathrm{BCV}$ was confirmed by the IF test, although only a limited crossreaction was obtained with HAI and NT assays and the monoclonal antibodies did not recognise shared epitopes. An antigenic relationship has been shown for each of the structural proteins of BCV strain M and HCV-OC43 [11]. These polyclonal antisera did not distinguish between the BCV strains by IF or NT, but showed a lower degree of crossreactivity in HAI particularly for strain $\mathrm{S} 1$. There is no evidence from this study of distinction of these BCV strains into classical serotypes.

The monoclonal antibodies reacted with separate epitopes on the BCV haemagglutinin protein, Mab/S 2/1 with an haemagglutinating epitope, Mab/S 2/ 2 with a non-haemagglutinating epitope, although both epitopes were obviously separately involved in virus neutralisation. It is of interest that the epitope reacting with $\mathrm{Mab} / \mathrm{S} 2 / 1$ allowed a very clear distinction by NT of BCV strains into those possessing this epitope (S2, M, and PQ), and those without (CK and $\mathrm{S} 1$ ). By contrast, the IF results showed poor reactivity with $\mathrm{M}$ and $\mathrm{S} 1$, and the HAI results showed low reactions only with $\mathrm{S} 1$. It is possible that this is a large epitope containing separate sequences responsible for each serological function accounting for the varying strain relationships. However, the distinction of strain S1 runs consistently through these results which confirms the 
findings with polyclonal reagents. There was a marked difference in the relative titres of MAB/S 2/1 for the M strain in the HAI and IF tests. No such difference was detected with any of the other strains.

The $5 \mathrm{BCV}$ strains examined were clearly closely related, to an extent that would be likely to confer in vivo crossprotection. It will be useful to compare a larger number of BCV strains with both polyclonal and monoclonal reagents to further investigate possible strain variation.

\section{References}

1. Archetti I, Horsfall FL (1950) Persistent antigenic variation of influenza A viruses after incomplete neutralization in vivo with heterologous immune serum. J Exp Med 92: $441-462$

2. Brian DA, Hogue B, Lapps W, Potts B, Kapke P (1983) Comparative structure of coronaviruses. In: Proceedings, Fourth International Symposium on Neonatal Diarrhea. VIDO, Saskatchewan, pp 100-115

3. Dea S, Roy RS, Begin ME (1980) Physicochemical and biological properties of neonatal calf diarrhoea coronaviruses isolated in Quebec and comparison with the Nebraska calf coronavirus. Am J Vet Res 41: 23-29

4. Dea S, Roy RS, Elazhary M (1982) Antigenic variations among calf diarrhoea coronaviruses by immunodiffusion and counterimmuno-electrophoresis. Ann Rech Vet 13: 351-356

5. Deregt D, Crouch CF, Sabara MI, Gilchrist J, Babiuk LA, Hudson GR (1983) Preliminary studies of a bovine coronavirus (BCV) antigen responsible for neutralization. In: Proceedings, Fourth International Symposium on Neonatal Diarrhea. VIDO, Saskatchewan, pp 117-132

6. Deregt D, Babiuk LA (1987) Monoclonal antibodies to bovine coronavirus: characteristics and topographical mapping of neutralizing-epitopes on the E2 and E 3 glycoproteins. Virology 161: 410-420

7. Deregt D, Sabara M, Babiuk L (1987) Structural proteins of bovine coronavirus and their intracellular processing. J Gen Virol 68: 2863-2877

8. El-Ghorr AA, Snodgrass DR, Scott FMM (1988) Evaluation of an immunogold electron microscopy technique for detecting bovine coronavirus. J Virol Methods 19: 215224

9. Gerna G, Passarani N, Battaglia M, Rondanelli EG (1985) Human enteric coronaviruses: antigenic relatedness to human coronavirus $O C 43$ and possible etiologic role in viral gastroenteritis. J Infect Dis 151: 796-803

10. Hajer I, Storz J (1979) Structural polypeptides of the enteropathogenic bovine coronavirus strain Ly-138. Arch Virol 59: 47-57

11. Hogue BG, King B, Brian DA (1984) Antigenic relationships among proteins of bovine coronavirus, human respiratory coronavirus $\mathrm{OC} 43$, and mouse hepatitis coronavirus A 59. J Virol 51: 384-388

12. Laporte J, Bobulesco P (1981) Polypeptide structure of bovine enteritic coronavirus: comparison between a wild strain purified from feces and HRT 18 cell adapted strain. Adv Exp Med Biol 142: 181-184

13. Mebus CA, Stair EL, Rhodes MB, Twiehaus MF (1973) Neonatal calf diarrhea: propagation, attenuation, and characteristics of a coronavirus-like agent. Am J Vet Res 34: 145-150

14. Reynolds DJ, Debney TG, Hall GA, Thomas LH, Parsons KR (1985) Studies on the relationship between coronaviruses from the intestinal and respiratory tracts of calves. Arch Virol 85: 71-83 
15. Sato K, Inaba Y, Kurogi H, Takahashi E, Satado K, Omori T, Matumoto M (1977) Hemagglutination by calf diarrhea coronavirus. Vet Microbiol 2: 83-87

16. Vautherot JF (1981) Plaque assay for titration of bovine enteritic coronavirus. J Gen Virol 56:451-455

17. Wege H, Siddell S, Ter Meulen V (1982) The biology and pathogenesis of coronaviruses. Curr Top Microbiol Immunol 99: 165-200

18. Wyatt RG, Greenberg HB, James WD, Pittman AL, Kalica AR, Flores J, Chanock RM, Kapikian AZ (1982) Definition of human rotavirus serotypes by plaque reduction assay. Infect Immun 37: 110-115

Authors' address: Dr. D. R. Snodgrass, Moredun Research Institute, 408 Gilmerton Road, Edinburgh EH 17 JH, Scotland.

Received November 15, 1988 